\title{
Eugenics scandal reveals silence of Swedish scientists
}

[PARIS] Revelations that successive Swedish governments sterilized more than $\mathbf{6 0 , 0 0 0}$ people on eugenic, social and economic grounds over 40 years, and until as recently as 1976, have exposed the failure of the Swedish scientific and medical communities to speak out against the practice.

The scandal broke last week following the publication of a series of articles in the Swedish newspaper Dagens Nyheter. Until then, few Swedes knew anything about the sterilization programme, even though its existence had hardly been a state secret. During the 1970s a parliamentary commission debated the 1934 law authorizing the sterilizations. The impact of the law, which was abolished in 1976, has also been widely debated in academic circles recently.

Mattias Tyden, a researcher in the history department at the University of Stockholm and an expert on eugenics, said a broad consensus existed in the scientific and medical communities and across political parties that the introduction of the sterilization programme was a "scientific and modern way of changing society for the better".

Although some individuals questioned the justification for the programme from the outset, their view remained a minority one, said Tyden, who points out that a parliamentary commission set up during the 1930 s concluded that the programme raised no particular ethical issues. Even after the Holocaust, Swedish society "did not see the parallels", he added.

Although the programme had its origins in the eugenics movement - in 1922, Sweden became the first country to create an institute for racial biology — its emphasis quickly shifted away from racial eugenics and towards social and economic goals. Whereas most sterilizations in the 1940s involved mentally handicapped individuals, the majority in the following decades were on women in difficult social circumstances. Some experts say that these sterilizations were carried out to meet these specific circumstances, without any intention of altering the overall composition of the population.

Sterilizations carried out on the basis of eugenic goals peaked in 1944 with 1,437 operations, compared with just 233 on social and economic grounds. But by 1954 , sterilizations performed on eugenic grounds had fallen to 204, while those for social and economic reasons had soared to 1,571 .

The widely held view was that sterilization was a "human solution" to improving the circumstances of misfits while reducing the social and economic burden they placed on

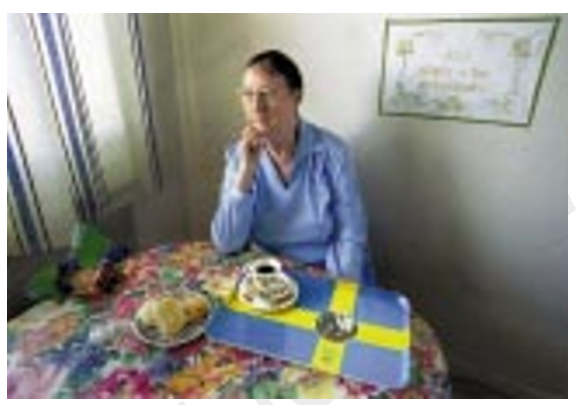

Swedish legacy of eugenics: Maria Nordin was forced to undergo sterilization in 1938.

society, said Tyden. The law was abolished only after growing opposition from victims and women's movements during the 1960s, and in particular as a result of campaigning in the early 1970s by Karl Grunewald, an inspector at the National Board of Health.

The Swedish scientific and medical community has so far been relatively silent on the subject. The Swedish national medical association declined to comment, claiming that such policy issues fall outside its remit. The Swedish Union of Physicians has not yet taken any position on the issue, according to Elisabeth Frustel, a spokeswoman for the organization, who said that physicians were "working within the law".

Declan Butler 